Research Article

\title{
Subcutaneous pressure in cellulitis of the leg: can it be a predictor for early surgical intervention?
}

\author{
Abinaya R. Nadarajan*, Suchita Chase, Beulah Roopavathana, Sukria Nayak
}

Department of General Surgery, Christian medical college and hospital, Vellore, Tamilnadu, India

\author{
Received: 23 April 2016 \\ Revised: 24 May 2016 \\ Accepted: 28 May 2016

\section{*Correspondence:} \\ Dr. Abinaya R Nadarajan, \\ E-mail: dr.abinayanadarajan@gmail.com
}

Copyright: (C) the author(s), publisher and licensee Medip Academy. This is an open-access article distributed under the terms of the Creative Commons Attribution Non-Commercial License, which permits unrestricted non-commercial use, distribution, and reproduction in any medium, provided the original work is properly cited.

\begin{abstract}
Background: Cellulitis, an infection of skin and subcutaneous tissue is usually managed conservatively and surgical intervention is required for local complications. The aim of this study was to correlate the subcutaneous pressure with the need for early surgical intervention in cases of lower limb cellulitis.

Methods: We prospectively measured subcutaneous pressures in the normal leg and in the leg with cellulitis. Patients managed with parenteral antibiotics were compared to those managed with parenteral antibiotics and surgical intervention with standard statistical tests.

Results: The median subcutaneous pressure was $3 \mathrm{mmHg}$ and $9 \mathrm{mmHg}$ in the normal leg and the other with cellulitis respectively. The mean of difference in subcutaneous pressure in legs with cellulitis compared to normal legs was $5.93 \mathrm{mmHg}$ and $8.29 \mathrm{mmHg}$ in the conservative group and surgical intervention group respectively. The difference in subcutaneous pressure between the normal leg and in the leg with cellulitis was statistically significant $(\mathrm{p}<0.001)$. The difference in the average pressure between surgical intervention group and conservative group was $2.36 \mathrm{mmHg}$ and was statistically significant $(\mathrm{p}<0.05)$. The optimal threshold (difference in pressure) was identified as $>=7$ with sensitivity of $85.7 \%$ and specificity of $57.1 \%$. Area under the ROC curve (SE) was $0.71(0.10)$ with $95 \%$ CI $(0.51,0.87)$.

Conclusions: The subcutaneous pressure in leg with cellulitis is a predictor for the need for early surgical intervention. It can be used as an adjunct in management and clinical decision making for cases of cellulitis of lower limbs.
\end{abstract}

Keywords: Cellulitis, Subcutaneous pressure, Superficial subcutaneous fasciotomy

\section{INTRODUCTION}

Cellulitis is a spreading bacterial infection of the dermis and subcutaneous tissues. It occurs among both men and women. ${ }^{1}$ The incidence of lower limb cellulitis was reported relatively high with 199 cases per 100,000 person-years in a population based study. ${ }^{2}$ The most common causative organisms are Streptococcus pyogenes and Staphylococcus aureus. ${ }^{3}$ The risk factors are toe web intertrigo, leg ulcers, trauma causing breach in the skin continuity, venous insufficiency, lymphedema, diabetes, obesity and immuno-compromised conditions. The most common risk factors for recurrence are venous insufficiency and lymphedema and previous episode of cellulitis. ${ }^{4}$ The most common pathogenesis is the breach in skin integrity especially the toe web space. The Streptococci and Staphylococci produce toxins which cause inflammatory mediator release, resulting in the edema and skin changes. ${ }^{5}$ If the infection is persisting in the subcutaneous plane, the edema worsens leading to local complications resulting in systemic sepsis and multiple organ dysfunction. The common clinical 
presentations are pain, swelling and redness of the leg with fever. Systemic symptoms like fever and raised white cell counts were present in $42 \%$ of the individuals at the time of admission. ${ }^{6}$ The treatment for cellulitis is administration of oral or parenteral antibiotic depending on the severity of cellulitis. Surgical intervention is required in patients developing local complications prolonging hospital stay, increasing the cost burden for hospital services. ${ }^{7}$ There are currently no easily quantifiable criteria or measurable evidence in literature for need for early surgical intervention in cellulitis.

\section{Study background}

The subcutaneous space is a superficial closed space (Figure 1). The normal subcutaneous pressure of the leg varies from -4 to $+4 \mathrm{mmHg}^{8}$ In chronic venous insufficiency, releasing the subcutaneous fluid by subcutaneous fasciotomy decreases the subcutaneous pressure. ${ }^{9}$ The same principle is applied in the management of cellulitis. Early superficial subcutaneous fasciotomy in cellulitis can prevent the local complication like skin necrosis and progression to necrotising soft tissue infection. This can also prevent extensive debridement and prolonged hospital stay subsequently. There are no objective criteria or predictors for early subcutaneous fasciotomy. The decision for subcutaneous fasciotomy is based on subjective assessment of the treating surgeons.

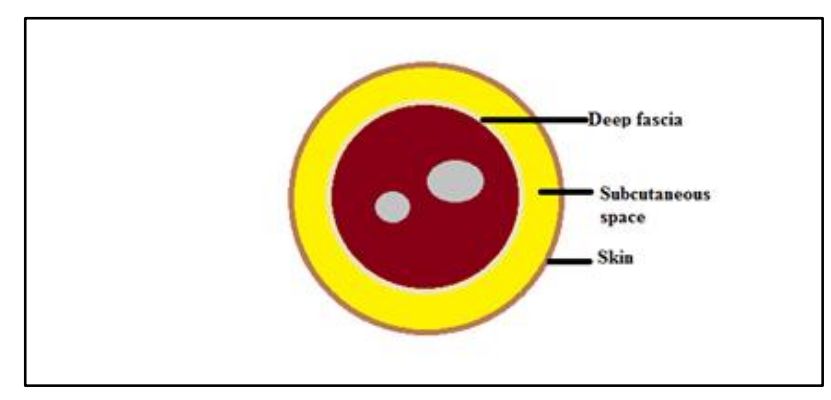

Figure 1: Cross sectional image of the leg showing the subcutaneous space.

\section{METHODS}

We prospectively studied patients with unilateral cellulitis of the leg admitted in Department of General Surgery, Christian Medical College, Vellore, between January 2012 and October 2013. Cellulitis of the leg was defined by presence of pain, swelling and erythema of the leg. Patients with subcutaneous abscess, necrotisisng soft tissue infection, leg ulcers or skin necrosis, chronic lymphedema, bilateral cellulitis, deep vein thrombosis and partially treated celluilitis of the leg were excluded.

Demographic data, symptoms, signs and comorbid illnesses were documented after obtaining informed consent from patients. The site of maximum swelling with tenderness in the leg with cellulitis was identified and the circumference of the leg was measured. The distance of this site was measured from tibial tuberosity in the leg with cellulitis. The circumference of the normal leg was measured at the same distance from tibial tuberosity. After local anaesthetic cream application, the subcutneous pressure was measured at one point in the normal leg and at 4 points in the leg with cellulitis at the same distance from tibial tuberosity. In the leg with cellulitis, the subcutaneous pressure was measured at 4 different sites (anteromedial, anterolateral, posteromedial and posterolateral) along the highest circumference of the leg with maximum swelling and tenderness. Four different sites were used for measurement as cellulitis with edema is not always circumferential.

The subcutaneous pressure was measured with Stryker intra compartmental pressure monitor and 18 gauge side port needle with saline prefilled syringe. ${ }^{10}$ The needle was inserted at an angle of 45 degree with the skin. The tip of the needle with side port was inserted into the subcutaneous space and $1 \mathrm{cc}$ of saline was injected. After waiting few seconds pressure reading was taken (Figure 2). The stable pressure value was documented in the normal leg and the monitor was reset to measure subcutaneous pressure at different sites in the leg with cellulitis. The subcutaneous pressure was measured at the time of admission for all the 28 patients and they were followed up. Out of 28 patients, 14 patients received only parenteral antibiotics and other 14 patients underwent surgery along with parenteral antibiotics either at the time of admission or later due to local or systemic complications as assessed by the treating surgeon.

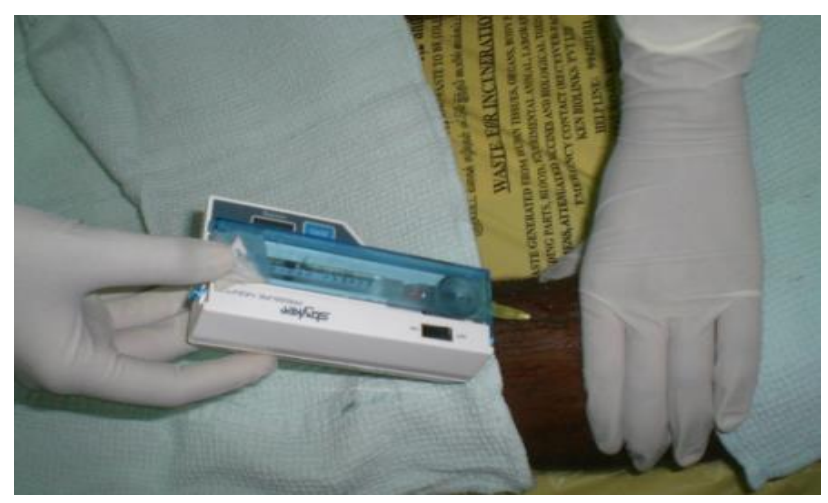

Figure 2: The subcutaneous pressure measurement in the leg with Stryker intracompartental pressure monitor. The subcutaneous pressure in the anterior aspect of leg with cellulitis is measured.

\section{Statistical analysis}

Frequency distribution with percentages was used to describe categorical data while descriptive statistics (e.g. mean, median, standard deviation) were obtained for continuous variables. We used Shapiro Wilk test to check for the normality assumption of the distribution of the data for choosing statistical tests. Comparison of 
difference in the circumference and the pressure of the normal leg and leg with cellulitis was done using paired $t$ test or Wilcoxon signed rank test depending on the distribution of the data. Comparison of pressure measured at four different sites of leg with cellulitis was done using paired t test. We define the maximum pressure in the leg with cellulitis as the highest pressure measured at the four different sites for further analysis. The difference in the effect of distance measured from tibal tuberosity on the pressure measured in the leg with cellulitis was answered by using Kruskal Wallis test. The difference in the pressure measured between normal and the maximum pressure in the leg with cellulitis was calculated. The mean difference in subcutaneous pressures between the surgery and the antibiotic only group was tested using two tailed independent sample t-test and also presented with $95 \%$ Confidence Interval (CI).

Receiver operating characteristic (ROC) curve analysis was also performed to calculate the area under the receiver operating characteristic curve (AUROC) of the difference in pressure between normal leg and leg with cellulitis. This was done to evaluate the ability of the difference in pressure to discriminate among patient who underwent surgery and those who received antibiotics alone. The optimal threshold values were calculated to maximize the sum of sensitivity and specificity. Positive likelihood ratio $(\mathrm{LR}+)$ and Negative likelihood ratio (LR-) were also calculated.

\section{RESULTS}

From January 2012 to October 2013, 28 patients with cellulitis of the leg were included in this study. Clinical characteristics of these patients are shown in Table 1. The majority of patients were older men with Diabetes mellitus. Nearly all patients had all the classical symptoms and signs of cellulitis.

The antibiotic group and surgical intervention group had equal number of patients (14 in each group) at the end of the study. There was no statistical difference in the sociodemographic and clinical characteristics of patients between the two groups. The antibiotics used to treat cellulitis were crystalline penecillin $(n=24 ; 85.7 \%)$, cloxacillin $(n=24 ; 85.7 \%)$, cefazolin $(n=1 ; 3.6 \%)$ piptaz and clindamycin $(n=3 ; 10.7 \%)$.

In the group of patients who had antibiotic and surgery (14), one patient underwent superficial subcutaneous fasciotomy within 24 hours and rest underwent surgery (subcutaneous fasciotomy, abscess drainage or debridement) later due to local or systemic complications. Those who were eventually operated received antibiotics for an average of three days prior to surgery.

The differences between group of patients treated conservatively with antibiotics alone and those managed with antibiotics and surgery were not statistically significant on the following variables: age, gender, diabetes mellitus, hypertension, renal failure, presence of swelling, erythema, warmth, and tenderness.

Table 1: Patient characteristics.

\begin{tabular}{|c|c|c|c|}
\hline Variables & No. $(\%)$ & $\begin{array}{l}\text { Mean } \\
\text { (SD) }\end{array}$ & $\begin{array}{l}\text { Median(IQ } \\
\text { R) }\end{array}$ \\
\hline $\begin{array}{l}\text { Age- } \\
\text { years(mean, } \\
\text { SD) }\end{array}$ & $\begin{array}{l}59.2 \\
(12.8)\end{array}$ & & \\
\hline \multicolumn{4}{|l|}{ Gender } \\
\hline Male & $23(82.1)$ & & \\
\hline Female & $5(17.9)$ & & \\
\hline \multicolumn{4}{|l|}{ Symptoms } \\
\hline Pain & $28(100)$ & & \\
\hline Swelling & $28(100)$ & & \\
\hline Fever & $27(96.4)$ & & \\
\hline \multicolumn{4}{|l|}{$\begin{array}{l}\text { Co- } \\
\text { morbidities }\end{array}$} \\
\hline Diabetes & $18(64.3)$ & & \\
\hline Hypertension & $6(21.4)$ & & \\
\hline Renal failure & $4(14.3)$ & & \\
\hline \multicolumn{4}{|l|}{ Signs } \\
\hline Swelling & $28(100)$ & & \\
\hline Erythema & $22(78.6)$ & & \\
\hline Warmth & $28(100)$ & & \\
\hline Tenderness & $28(100)$ & & \\
\hline \multicolumn{4}{|c|}{ Circumference $(\mathrm{cm})$} \\
\hline Normal leg & & $28.1(6.3)$ & \\
\hline $\begin{array}{l}\text { Leg with } \\
\text { cellulitis }\end{array}$ & & $31.9(7.1)$ & \\
\hline $\begin{array}{l}\text { Distance at } \\
\text { which } \\
\text { subcutaneous } \\
\text { pressure } \\
\text { measured } \\
\text { from tibial } \\
\text { tuberosity }(\mathrm{cm})\end{array}$ & & $16.4(5.4)$ & \\
\hline \multicolumn{4}{|l|}{$\begin{array}{l}\text { Subcutaneous } \\
\text { pressure } \\
(\mathrm{mmHg})\end{array}$} \\
\hline Normal leg & & & $3.0(-0.5,5.0)$ \\
\hline \multicolumn{4}{|l|}{$\begin{array}{l}\text { Leg with } \\
\text { cellulitis }\end{array}$} \\
\hline Anteromedial & & & $7.5(4.0,10.8)$ \\
\hline Anterolateral & & & $6.0(4.3,8.0)$ \\
\hline Posteromedial & & & $6.0(4.0,10.0)$ \\
\hline Posterolateral & & & $6.0(3.3,7.8)$ \\
\hline $\begin{array}{l}\text { Maximum } \\
\text { pressure }\end{array}$ & & & $9.0(7.0,12.0)$ \\
\hline
\end{tabular}

No.- Number; \%- Percentage; SD- standard deviation; IQRInterquartile range. Maximum pressure is the highest pressure measured at four different sites in leg with cellulitis.

There was no statistical difference in subcutaneous pressures measured at four different sites (anteromedial, anterolateral, posteromedial, posterolateral) in the leg with cellulitis at the same distance from tibial tuberosity. 
However, the maximum subcutaneous pressure in leg with cellulitis correlated to maximum site of induration and swelling. The effect of distance from tibial tuberosity on the subcutaneous pressure measured was statistically analysed because the subcutaneous pressure was measured at different levels for each patient. However, there was no statistical difference noted for the distance from tibial tuberosity. Subcutaneous pressures and the comparisons are shown in Table 2 . The results suggest that there is a statistically significant difference between the underlying distributions of the subcutaneous pressure in normal leg and the subcutaneous pressure in leg with cellulitis $(\mathrm{z}=-4.63, \mathrm{p}=<0.001)$. The difference in the average pressure between antibiotic with surgery and antibiotic alone group was 2.36 (95\% CI: 0.23, 4.49) and also reached statistical significance.

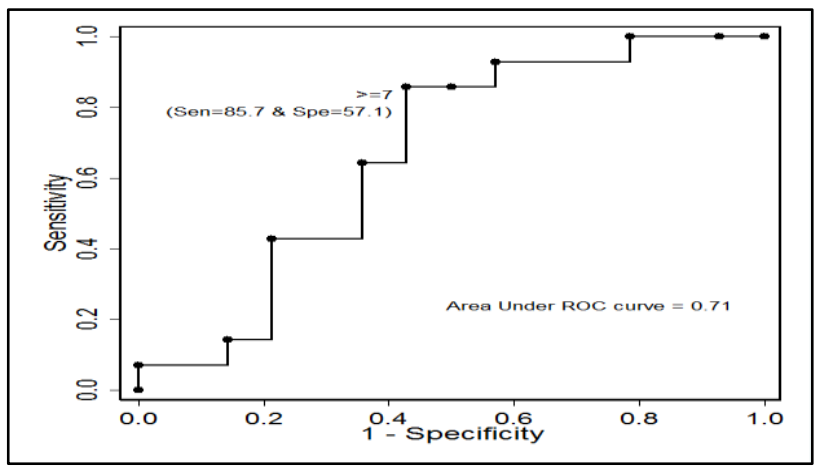

Figure 3: Receiver operator characteristic curve comparing difference in subcutaneous pressure between normal leg and leg with cellulitis against the gold standard of the clinical decision for surgical intervention.

The increase in subcutaneous pressure between the antibiotic group and group managed with antibiotic and surgery is found to be statistically significant with a $\mathrm{p}$ value 0.032 .

Table 2: Subcutaneous pressures comparison between the normal leg and in leg with cellulitis.

\begin{tabular}{|c|c|c|c|}
\hline & $\begin{array}{l}\text { Median } \\
\text { (Min, Max) }\end{array}$ & $\mathbf{Z}$ statistics & P-value \\
\hline \multicolumn{4}{|c|}{$\begin{array}{l}\text { Comapring pressures in normal leg and in leg with } \\
\text { cellulitis }\end{array}$} \\
\hline $\begin{array}{l}\text { Pressure in } \\
\text { normal leg } \\
(\mathrm{mmHg})\end{array}$ & $3(-4,6)$ & -4.63 & $<0.001$ \\
\hline $\begin{array}{l}\text { Maximum } \\
\text { pressure in } \\
\text { leg with } \\
\text { cellulitis } \\
\text { (mmHg) }\end{array}$ & $9(4,16)$ & & \\
\hline \multicolumn{4}{|c|}{$\begin{array}{l}\text { Comparing pressures in leg with cellulitis in group } \\
\text { manged with antibiotics alone with those manged by } \\
\text { antibiotics and surgery }\end{array}$} \\
\hline & Mean (SD) & t statistics; df & $\begin{array}{l}\mathbf{P} \\
\text { value }\end{array}$ \\
\hline $\begin{array}{l}\text { Antibiotics } \\
\text { alone }\end{array}$ & $5.93(2.73)$ & $2.27 ; 26$ & 0.032 \\
\hline $\begin{array}{l}\text { Antibiotics } \\
+ \text { surgery }\end{array}$ & $8.29(2.76)$ & & \\
\hline
\end{tabular}

Table 3 documents the sensitivity, specificity and likelihood ratios for different threshold of difference in subcutaneous pressures between between the normal leg and the leg with cellulitis.. The optimal threshold (difference in pressure) was identified as $>=7$ with sensitivity of $85.7 \%$ and specificity of $57.1 \%$ fig 3. Area under the ROC curve (SE) was $0.71(0.10)$ with $95 \%$ CI $(0.51,0.87)$. This analysis was done to find out the cut off for surgical intervention.

Table 3: Sensitivity, specificity and likelihood ratios with different thresholds of subcutaneous pressure differences between normal leg and leg with cellulitis.

\begin{tabular}{|lllll|}
\hline Threshold & Sensitivity $(\%)$ & Specificity $(\%)$ & LR+ & LR- \\
\hline$>=2$ & 100.00 & 0.00 & 1 & - \\
\hline$>=3$ & 100.00 & 7.14 & 1.08 & 0 \\
\hline$>=4$ & 100.00 & 21.43 & 1.27 & 0 \\
\hline$>=5$ & 92.86 & 42.86 & 1.63 & 0.17 \\
\hline$>=6$ & 85.71 & 50.00 & 1.71 & 0.29 \\
\hline$>=7$ & 85.71 & 57.14 & 2.00 & 0.25 \\
\hline$>=8$ & 64.29 & 64.29 & 1.80 & 0.56 \\
\hline$>=9$ & 42.86 & 78.57 & 2.00 & 0.73 \\
\hline$>=10$ & 14.29 & 85.71 & 1.00 & 1.00 \\
\hline$>=16$ & 7.14 & 100.00 & - & \\
\hline$>=17$ & 0.00 & 100.00 & - & 0.93 \\
\hline
\end{tabular}




\section{DISCUSSION}

This study, to the best of our knowledge, is the first to study subcutaneous pressures in legs of people with cellulitis. The study population was similar to that described in literature with a predominance of older people and men. ${ }^{3,11,12}$ The clinical presentations were also classical with diabetes mellitus as a major risk factor., ${ }^{43-16}$ Most of the patients received Inj crystalline penicillin and cloxacillin for Streptococci and Staphylococci. ${ }^{13}$

Subcutaneous pressures were elevated in patients with cellulitis of the leg when compared to the normal leg. The increase in subcutaneous pressure in leg with cellulitis was significantly higher in group of patients who underwent surgery.

The differences in subcutaneous pressure between the normal and the leg with cellulitis is measurable. The results of this study suggest that correlating the difference in the subcutaneous pressures between a normal and affected leg will be of use in clinical decision making for surgical intervention.

\section{CONCLUSION}

Decision for early surgical intervention in managing cellulitis of the leg is usually based on the surgeon's experience and clinical decision-making skill. However, measuring subcutaneous pressure will allow the surgeons to make a decision for early surgical intervention and prevent local complications, extensive debridement which prolong the hospital stay and cost of management in lower limb cellulitis.

Funding: No funding sources Conflict of interest: None declared

Ethical approval: The study was approved by the institutional ethics committee

\section{REFERENCES}

1. Morris AD. Cellulitis and erysipelas. BMJ Clin Evid. 2008; 2008: 1708.

2. McNamara DR, Tleyjeh IM, Berbari EF, Lahr BD, Martinez JW, Mirzoyev SA, et al. Incidence of lower-extremity cellulitis: a population-based study in Olmsted County, Minnesota. 2007;82(7):817-21.

3. Maitre S. Cellulitis: definition, etiology, diagnosis and treatment. Virtual Mentor. 2006;8(12):831-3.

4. Ch'ng CC, Johar A. Clinical characteristics of patients with lower limb cellulitis and antibiotic usage in Hospital Kuala Lumpur: a 7-year retrospective study. Int J Dermatol. 20161;55(1):305 .

5. Baddour LM, Googe PB, Prince TL. Possible role of cellular immunity: a case of cellulitis. Clin Infect Dis Off Publ Infect Dis Soc Am. 2001;32(1):E1721.

6. Aly AA, Roberts NM, Seipol KS, MacLellan DG. Case survey of management of cellulitis in a tertiary teaching hospital. Med J Aust. 1996;165(10):553-6.

7. Kameshwar K, Karahalios A, Janus E, Karunajeewa H. False economies in home-based parenteral antibiotic treatment: a health-economic case study of management of lower-limb cellulitis in Australia. J Antimicrob Chemother. 2016;71(3):830-5.

8. Christenson JT, Al-Hassan HK, Shawa NJ. Subcutaneous and intramuscular pressures in the post-phlebitic limb. Scand J Clin Lab Invest. 1986;46(2):137-41.

9. Christenson JT. Post thrombotic or non-post thrombotic severe venous insufficiency: impact of removal of superficial venous reflux with or without subcutaneous fasciotomy. J Vasc Surg. 2007;46(2):316-21.

10. Boody AR, Wongworawat MD. Accuracy in the measurement of compartment pressures: a comparison of three commonly used devices. J Bone Joint Surg Am. 2005;87(11):2415-22.

11. Simonsen SME, Orman ERV, Lyon JL . Cellulitis incidence in a defined. Epidemiol Infect. 2006;134(2):293-9.

12. Ch'ng CC, Johar A. Clinical characteristics of patients with lower limb cellulitis and antibiotic usage in Hospital Kuala Lumpur: a 7 year retrospective study. Int J Dermatol. 2016;55(1):305.

13. Bailey E, Kroshinsky D. Cellulitis: diagnosis and management. Dermatol Ther. 2011;24(2):229-39.

14. Phoenix G, Das S, Joshi M. Diagnosis and management of cellulitis. BMJ. 2012;345:e4955.

15. Karppelin M, Syrjänen J, Siljander T, VuopioVarkila J, Kere J, Huhtala H, et al. Factors predisposing to acute and recurrent bacterial nonnecrotizing cellulitis in hospitalized patients: a prospective case control study. Clin Microbiol Infect. 2010;16(6):729-34.

16. Bruun T, Oppegaard O, Kittang BR, Mylvaganam H, Langeland N, Skrede S. Etiology of cellulitis and clinical prediction of streptococcal disease: a prospective study. Open Forum Infect Dis. 2016;3(1): 181 .

Cite this article as: Nadarajan AR, Chase $\mathrm{S}$, Roopavathana B, Nayak S. Subcutaneous pressure in cellulitis of the leg: can it be a predictor for early surgical intervention?. Int Surg J 2016;3:1218-22. 